\title{
The Advantages and Limits of ICT in the Teaching and Learning of Foreign Languages in Yemen
}

\author{
Fares Al Ameri \\ Department of French Language, Faculty of Arts, University of Sana'a, Sana'a, Yemen \\ Email address: \\ fgassare@yahoo.fr \\ To cite this article: \\ Fares Al Ameri. The Advantages and Limits of ICT in the Teaching and Learning of Foreign Languages in Yemen. International Journal of \\ Applied Linguistics and Translation. Vol. 7, No. 3, 2021, pp. 116-121. doi: 10.11648/j.ijalt.20210703.15
}

Received: August 2, 2021; Accepted: August 21, 2021; Published: September 10, 2021

\begin{abstract}
This article is intended to show the importance of information and communication technology (ICT) in the teaching and learning of foreign languages and cultures. It is obvious that learning a foreign language is always accompanied by learning the culture. When speaking a language, we often refer to its culture which facilitates the communications with the other. Thus, we cannot speak a foreign language without knowing its cultural reference because the language and its culture are inseparable. But how can you learn a foreign culture without immersing yourself in the society that speaks this language? Technology therefore sees itself playing the role of cultural mediator between the learner of this foreign language and the society that speaks that language. The insertion of the technology certainly has strengths, but it must also have drawbacks that can hinder the learning process. Therefore to be useful, the insertion of the technology in foreign language education should not be hold according to general indications but in relation to every context's specificities.
\end{abstract}

Keywords: ICT, Teaching, Learning, FFL, Yemen

\section{Introduction}

Technology is a very important means of contact and communication in our society today. The new technology of information and communication represent all the techniques of the areas of audiovisual, computer, Internet, telecommunications and multimedia that can be communicated to and share the many sources of information in their different shapes (text, music, image, video ...) ${ }^{1}$ [5]. It is increasingly used in different scientific fields, including the field of teaching / learning foreign languages and cultures. ICT is seen as a tool that facilitates the teaching / learning of foreign languages. It is thus put at the service of the educational operation. But what is ICT and how can it be integrated in the field of teaching and learning foreign languages? What are the essential conditions for the integration of ICT? What are the limitations of ICT that we must take into account when integrating them into the educational process? Is technology capable of facilitating

1 - Durant Axelle, 2020: "New technology. World and school of tomorrow" in Analyse, $\mathrm{n}^{\circ}$ 416, 2020, Brussels.p. 4. www.cpcp.be/publications/nouvelletechnologie. accessed 11-8-2021 access to the culture of the other? These are the questions we must answer in this article.

In this article we will first show the importance of the integration of ICT in the teaching / learning of foreign languages. We will then show the contributions of technology and how we must proceed to integrate it well into the foreign language classroom: the conditions and arrangements. Then we will talk about the limits of ICT that we must take into account when integrating them into the language class. We will also study the role of ICT in the teaching / learning of foreign culture. Finally, we refer from time to time to the Yemeni context and the constraints which are particularly linked to it in order to clarify our remarks.

\section{The Integration of ICT in Language Teaching}

Many researchers have criticized and questioned the "technocentric" who followed the first years of the appearance of computers ${ }^{2}[10]$. They insisted on the fact

2-Mangenot, Francoise: "Internet network and French learning" in Hypermedia and language learning, Studies in applied linguistics, $\mathrm{n}^{\circ} 110$, April-June 1998, pp. 
that technology should not be seen outside of educational design, but as a device at the service of language didactics and teaching methodology. It is obvious that we cannot act "as if the technologies did not exist, but the latter must be at the service of didactics and pedagogy." ${ }^{3}$ [13]. Thus, the process of teaching foreign languages and cultures should, in this sense, introduce the use of technologies and not the other way around. These must then be structured in the didactics of languages-cultures as supports and tools facilitating the educational operation. Indeed, the integration of ICT is not achieved by replacing tools in place of other more developed ones such as moving, for example, from teaching based completely on the textbook to a process that calls on ICT such as than the computer (EA O). On the other hand, it requires an arrangement of space and learning time, in view of the various tools available. It also implies a modification of pedagogical interactions and the role of actors (teacher and learner) ${ }^{4}$ [6]. The teacher becomes, following his training in ICT, a mediator between the learner and the machine.

In addition, the integration of ICT in language teaching consists of bringing together certain pedagogical conditions that raise questions of different kinds caused by the inclusion of these:

"A questioning of the attitude of teachers: what are their conceptions of the profession and how do they see their role within the institution?

A pragmatic questioning, which includes questions relating to the educational and institutional leeway granted to them or that they spare themselves, and to the training, material and financial means at their disposal within the establishments.

An epistemological questioning, for example their understanding of certain key concepts linked to the integration of ICTs such as the task or the development of language skills" ${ }^{4}[6]$.

It is therefore necessary to provide answers to these questions in order to optimize the integration of information and communication technology within the process of teaching / learning foreign languages and cultures. It is also important to question the teaching method in which the technological tool fits, which supposes a reflection before the implementation of ICT in this process. The designers of the program "must also take into account the adapted methods and the expected objectives because to speak about the efficiency of a teaching tool requires to refer to the methods in which this tool will take place and further still to the educational objectives which them underlying" ${ }^{5}$ [9]. Thus, the question of the integration of ICT / ICT requires taking into account two important elements: the way (the how) and the objectives (the why). It also involves ensuring

205-213.

3-Pothier, Michel 2003: Multimedia, language learning and acquisition devices, Ophrys, Paris, P. 121.

4-Guichon, Nicolas, 2012: Towards the integration of ICT in language teaching, Les Editions Didier, Paris, P. 45.

5-Lebrun, Monique, 1999: Technologies for teaching and learning, Deboeck, Coll. (Perspectives in education and training). Brussels, P. 146. consistency between the provision of IT tools in establishments and the training of teachers with regard to the introduction of ICT in the pedagogy of education and the teaching of foreign languages. The training of language teachers in the pedagogical use of ICT is essential insofar as the teacher is a decisive actor in the process of teaching and learning languages and cultures. Its importance stems from its major role as a mediator between ICT and learners, without which the interest of ICT would remain limited and would not lead to the expected objectives.

Finally, the contributions of ICT are numerous on the educational and social level. They lead learners to take into account the technological change that has occurred in today's world and its impacts on the perceptions and behaviors of human beings in their daily life and in the field of teaching and learning in redefining the relationship and the positions of the learner and the teacher in the educational process.

\section{The Contributions of ICT in Language Teaching}

We can see that the contribution of ICTs is not only exerted in the education system, but that it is also remarkably perceived at the social level. This influence is due to certain factors structured by technological evolution, in particular the elimination of parameters at the level of spatial distances and temporal links by increased access to networks. Technology thus marks an evolution in all areas of social life in which education can also contribute. It is thus the responsibility of the educational institution to pursue today's technical developments by training personnel capable of making use of this technology. The contributions of ICT in the field of teaching and learning are numerous, in particular in that of foreign languages and cultures. Thus, Narcy-Combes ${ }^{6}$ [12] offers a list of advantages provided by ICT in the field of teaching and learning of foreign languages and cultures:

1. The work on ICT supports can be part of the snapshot (set up of automatism)، but it also favors asynchronism and a more individualized management of time.

2. The learner is more physically active in front of a computer than seated in class. He "acts" more and therefore should learn more according to some theories.

3. ICTs promote permanent interactivity.

4. ICT allow individualization without isolation.

5. They allow the multi-channel so useful in our field (sound, image, text).

6. They are sources of multireferentiality, which allows cross-references and an attitude of relativization in the face of information.

7. They bring flexibility and creativity to the task level, in particular, they allow the learner to design his own tasks.

Referring to the list of Narcy-Combes, we will explain in detail the few points that contribute, from our point of view,

6 -Narcy-combe, Jean.Pierre, 2005: Language teaching and ICT: towards responsible action research, OPHRYS, Paris, P. 172. 
to the evolution of the teaching and learning of foreign languages and cultures. These points are also indicated by Abdallah-Pretceille and Porcher $^{7}[14]$. They advance the idea that the invention of the internet is marked by several parameters such as:

1. Equipment open to all, accessible, without discrimination (other than financial) and which does not require any prior skills in reading and writing.

2. This is the first truly interactive technology in the space of the entire planet. You can attend it from anywhere, register whatever you want.

3. The radical individualization of all communication is also ensured according to the wishes of the user".

Finally The ICT offers new methods and advantages of teaching/learning, especially in the field of the foreign languages ${ }^{8}[7]$.

\subsection{Individualization of Learning}

Unlike traditional courses which offer a shared objective for a given audience, the teaching and learning of languages, via ICTs such as distance learning, gives more individual freedom to the learner who will follow the operation. educational according to its needs, objectives and pace. It is important to point out that in the lessons, in language classes, the uniqueness of each learner is not fully taken into account despite the efforts of didacticians to specify their needs and their specificities. ICT enables learners to choose the place and time that is convenient for them to carry out activities and seek information. They can take their courses from home, the office or the resource center. This more individual approach does not, however, imply that the learner can appropriate a language on his own, without having recourse to educational programs or to teachers who guide his development. Rather, it is about working at your own pace, according to your interests and your own goals, without having to travel. Indeed, ICT allow learners to carry out their activities individually without losing contact with others, as Narcy-Combes points out when speaking of individualization without isolation. They also allow learners to work with flexibility, in particular in terms of the pace of learning, this flexibility being a driving force for increasing their creativity. Working according to this more personal rhythm, the student certainly increases his confidence and his motivation insofar as he gradually becomes aware of his capacity to carry out work independently and of his progress in learning. Thus, we can affirm that autonomy could be a generator of motivation and creation.

We should also point out that teaching / learning via ICT places an important place on individual work. Guided by the teacher who explains the key concepts to him and who creates files accessible to all around these concepts, the

7-Porcher Louis and Abdallah-pretceille, Martine, 1998: ethic of diversity and education, PUF,Pris, $\mathrm{p} 128$.

${ }^{8}$-Hocine, Naima, 2011: pedagogical interest of insertion of EICT in the teaching of FFL: Web-blog use in the writing activities, in Synergie Algerie, $n^{\circ} 21,2011$, pp 219-226. learner is encouraged to seek alone the information he needs. The encouragement of individual work leads the learner on the path of confidence and autonomy. Finally, autonomy is made more possible thanks to the individualization of the learning rhythms which gives the learner more confidence in himself and in his individual capacities.

\subsection{The Wealth of Resources (Multireferential)}

ICTs (online or offline) provide the learner with a wealth of information resources. The learner can, thanks to technology, easily access multireferential resources on the web. These are constantly expanding and becoming accessible to a majority of people in today's world. Thus, access to information was simplified and became available to everyone. Search engines such as Google provide researchers with a mass of information with multiple references posted online from different places on the planet. It should also be noted that on the web, the notion of borders is not present. Anyone can access information, as long as it is freely accessible, from any place in the world through a connection to networks (Wifi or Cable). However, some sites are not "free to access", that is to say they are not accessible to everyone. Access to these sites is often conditioned by a subscription or reserved for a category of people (students or researchers) accredited by passwords such as for example some university sites reserved for its students, researchers, professors. Moreover, this does not minimize the importance of information in free use.

1. It is important to note that the wealth of information resources is not restricted to online connection. There is also software that contains a lot of information and that we can consult offline, such as dictionaries or computer encyclopedias (Larousse). Finally, Demaizière ${ }^{9}$ [4] distinguishes three types of ICT resources that we can meet in technology products. They are classified according to their production objectives:

2. Educational resources: this kind of resources is mainly intended for educational objectives such as software or an educational site such as ALSIC, CIEP.

3. "Raw" resources: these are documents which are not designed for educational purposes such as, for example, authentic documents placed online or on a CD-ROM.

4. Raw pedagogical resources: these are raw documents that the pedagogy adapts for educational purposes, by giving instructions to the teacher to use them in the language class, such as the educational booklets which accompany some documentary films thus indicating the pedagogical stages to follow to introduce it into the language class".

ICTs are also synchronous or asynchronous communication and interactivity tools. They mark an important step in the field of teaching and learning of foreign languages and cultures insofar as they facilitate, within the

9-Demaiziere, Francoise, 2004: ICT and teaching / learning, generalities, on the Ganesha platform, online http: jalu // Ouvaton.org / Ganesha /. Accessed 313 2019. 
framework of teaching via ICT, exchanges between foreign and native students.

\subsection{Interactivity and Interaction}

Interactivity is one of the characteristics of the use of the Internet in the field of teaching / learning foreign languages and cultures. On the interactive level, the internet has, moreover, changed the intervention and exchange mechanisms concerning intercultural communication. It allows direct communication between learners from different cultures, over relatively long periods; it thus encourages the passage from an "object culture" to a "culture in action" 10 [11]. The learner no longer needs to understand the other's culture based only on data provided by the school, but it is possible for him to make direct contact with students belonging to this culture and to discuss with them on relevant topics concerning both cultures. The few educational projects set up with objectives aimed at intercultural exchanges such as Cultura (1997) or French in the "front line" (2002), have shown very encouraging results at the level of intercultural negotiation insofar as Programs encourage learners to connect with other learners who live in another country. It is, moreover, difficult to set up, in Yemen, a program like Cultura under current teaching conditions given the unavailability and absence, in most cases, of networks and computer equipment in educational establishments as well as the absence of training in the use of ICT among teachers. This program can, however, be reinvested and extended in other situations. It is through this type of project that the learner can access, by himself, the culture of the other.

\subsection{Facilitate Access to the Foreign Culture of the Other}

We must point out that ICTs have also facilitated contacts and access to the culture of others through the media. They mediate between the learner and the foreign culture ${ }^{11}[6]$. Technology facilitates access to information by making available to the learner the choice between different means and alternatives allowing to discover the foreign culture, in particular the direct contact or the search for information in the various multimedia resources.

Brodin $^{12}$ sees networks as facilitators of access to sources of information and to humans, opening the way to computermediated communication and allowing the development of collaborative work and the collective construction of knowledge through ICTs [2]. By means of the mediatized communication available thanks to ICT, the student will thus have the possibility of discovering the world and of decentering himself thereafter of any representation and

10-Mangenot, Francoise: "Forum and distance training: case study", in Education Permanente, $\mathrm{n}^{\circ} 152,2002$, pp. 109-119, online: http://www.educationpermanente.fr/public. Accessed 5122020.

11-Guichon, Nicolas, 2012: Towards the integration of ICT in language teaching, Les Editions Didier, Paris, P. 45.

12 -Brodin, Elsabeth, 2016: "Innovation, technological instrumentation of language learning: from action schemes to models of emerging practices", in ALSIC 2002, vol. 5, $\mathrm{n}^{\circ}$ 2, pp. 149-181, online: http://alsic.revues.org/2070. Accessed March 3, 2019, p. 156. received ideas, resulting from his culture of belonging. Faced with this autoreferentiality of resources, the learner is thus led to think in front of this multitude of sometimes contradictory information which nevertheless allows him to consider the different points of view of one and the other on a given object.

In the context of our educational situation in Yemen, "collective intercultural representations of foreigners are omnipresent in the social life of the individual, in particular through religious discourse that promotes fear of foreigners and in particular "non- Muslims""1 ${ }^{13}$ [1]. Some learners are thus haunted by these often-distorted images of the West then perceived as the enemy of the nation and of Islam. It is thus important to bring the learner to discover and to constitute the image of the other by himself and to reject any preestablished representation or stereotype. The technology "initiates also the students to collaborate through these technological tools" ${ }^{14}$ [8]. This collaboration could be between the students of the same classroom or with equivalent students from other countries, under the supervision and organization of the tow schools from the tow countries and according to their coordination.

\section{Obstacles and Limits to the Integration of ICT}

The integration of ICT is not without difficulties and constraints. The contributions of ICT are often accompanied by limits and pitfalls. The limits are numerous and depending on each context, but we will be satisfied with the obstacles observed in our field, during our observation in language classes in Yemen (our field).

\subsection{Material Constraints}

We must therefore point out that the material constraint must always be taken into account, in particular in schools or universities. Obtaining these technological tools requires a significant financial budget for the purchase of equipment, their maintenance and their installation, which establishments do not always have at their disposal. In the Yemeni context, as an example, "the ministerial law promulgated in 2002 which aimed at the introduction of ICT in the national education program could not see the light of day due to financial problems" ${ }^{15}$ [15]. It was not until 2013 that this law reappeared on the table of discussions thanks to the efforts of UNESCO and some organizations concerned with education such as (GIZ) the

\footnotetext{
13 - Al ameri, Fares, 2019: "Interculturality: an approach to promote civil peace in current societies" in languages-cultures driving democracy and development, le croquan, paris. Ch9, pp 127-137.

${ }^{14}$-Koulayan, Nicole, 2019: "Today, for teaching foreign languages, contribution of numeric/digital is it a positive cognitive innovation?" in Archipelie, 7, 2019, connection 14-8-2021. pp 1-30. www.archippelies.org/50

${ }^{15}$-Seif, Ahmed, 2011: ICTs in the Yemeni education system: from the technical culture of Yemeni society to uses by education professionals, doctoral thesis in language sciences, defended on March 8, 2011, Strasbourg, University of Strasbourg, P. 52.
} 
German Agency for International Cooperation. The provision of technological materials is fundamental to be able to start a teaching project via ICT. This is the major problem that we can see today in the education system of underdeveloped countries like Yemeni. The inclusion of ICT in the language class also entails a certain knowledge of the use and handling of these tools, which also involves training of trainers.

\subsection{Lack of Technical and Techno-pedagogical Training}

The training of teachers in the use of ICT is an essential step for the realization of this type of project since it is their responsibility to know the technical handling of computer tools adapted to the teaching / learning of languages. It is also one of the principal hindrance faced in the development of education via $\operatorname{ICT}^{16}[3]$. The usefulness of technical manipulation is particularly evident when a technical problem arises in the language class. It is therefore up to the teacher to solve it in order to finally be able to carry out his course. To conclude, it is essential for the teacher to be able to handle the technical tools introduced in his language class. However, our Yemeni field experience shows that the majority of teachers working in the field of foreign language teaching do not have a good knowledge of the use of ICT. Following the technical training, techno-pedagogical training is also essential to train teachers in the introduction of ICT in the classroom of foreign languages to better use this device and to promote learning.

\subsection{The Proliferation of Uninsured Information}

One of the problems that we face in the use of ICT online or offline is related to the large amount of information, the credibility of which is not always certified. Within the framework of the discovery of the culture of the other via the TIC, it is incumbent on the researchers to take into account the Internet sources on which they can rely in the search for information. It is also interesting to find a lot of information available to the learner on a given subject. Yet is this information relevant and verified? Doesn't a little credible information run the risk of building a bad representation of others? Indeed, the profusion of similar educational or cultural resources obliges the actors (teachers and learners) to sort through the available information and, at the same time, raises the question of verifying the relevance of the content. It should therefore be pointed out that this multiplication of information, sometimes contradictory, is a source of disturbance for learners. We do not mean, in this sense, that the multiplication and wealth of information is harmful for the construction of our knowledge but that it is a question of being vigilant in the choice of references especially in an intercultural context.

\footnotetext{
${ }^{16}$ - Deloy Antoine, 2020: insertion of ICT in class of FFL: rapports, limits and role. The case of French Institute in Finland. Research defended in Aix en province university, Marseille, in archives-ouvertes.Fr. p. 20, consulted on 11-82021.
}

\section{Conclusion}

To conclude, technology is very important in the teaching / learning of foreign languages and cultures insofar as it allows students to get in touch with the foreign language and culture through software and websites that facilitate exchanges with students. native. It also allows them to learn, on their own, information about the language and culture in question. Thus, technology constitutes a considerable asset for development in the field of teaching / learning foreign languages and cultures.

In order not to receive negative results, it would be necessary to be aware of the measures which allow the successful integration of technology and the conditions which favor its integration. Teachers and learners should also be made aware of the limits of technology in the teaching / learning of foreign languages-cultures. We must also take into account the inequalities that the integration of technology can create in advantaged and economically disadvantaged students. These can also cause hatred and misunderstandings among students.

Finally, despite its limitations, technology remains an important asset in promoting the teaching / learning of foreign languages, especially in a country like Yemen where the practice of FFL remains rare there. Technology thus offers Yemeni FLE student's channels of contact with the French-speaking world that they cannot visit or make direct contact with.

\section{References}

[1] Al ameri, Fares, 2019: "Interculturality: an approach to promote civil peace in current societies" in languages-cultures driving democracy and development, Le Croquant, Paris, ch. 9, pp 127-137.

[2] Brodin, Elsabeth, 2016: "Innovation, technological instrumentation of language learning: from action schemes to models of emerging practices", in ALSIC 2002, vol. 5, $\mathrm{n}^{\circ} 2$, pp. 149-181, online: http://alsic.revues.org/2070. Accessed 33-2019, p. 156.

[3] Deloy Antoine, 2020: insertion of ICT in class of FFL: rapports, limits and role. The case of French Institute in Finland. Research defended in Aix en province University, Marseille, in archives-ouvertes.Fr. Consulted 11-8-2021.

[4] Demaiziere, Francoise, 2004: ICT and teaching / learning, generalities, on the Ganesha platform, online http:jalu//Ouvaton.org/Ganesha/. Accessed 31-3-2019.

[5] Durant Axelle, 2020: "New technology. World and school of tomorrow" in Analyse, $\mathrm{n}^{\circ}$ 416, 2020, Brussels. www.cpcp.be/publications/nouvelle-technologie. accessed 118-2021.

[6] Guichon, Nicolas, 2012: Towards the integration of ICT in language teaching, Les Editions Didier, Paris, P. 46.

[7] Hocine, Naima, 2011: pedagogical interest of insertion of EICT in the teaching of FFL: Web-blog use in the writing activities, in Synergie Algerie, $\mathrm{n}^{\circ} 21,2011$, pp 219-226. 
[8] Koulayan, Nicole, 2019: today, for teaching foreign languages, contribution of numeric/digital is it a positive cognitive innovation? Archipelie, 7, 2019, connection 14-82021. www.archippelies.org/50

[9] Lebrun, Monique, 1999: Technologies for teaching and learning, Deboeck, Coll. (Perspectives in education and training). Brussels, P. 146.

[10] Mangenot, Francoise, 1998: "Internet network and French learning" in Hypermedia and language learning, Studies in applied linguistics, $\mathrm{n}^{\circ}$ 110, April-June 1998, pp. 205-213.

[11] Mangenot, Francoise, 2002: "Forum and distance training: case study", in Education Permanente, $\mathrm{n}^{\circ} 152,2002$, pp. 109119, online: http://www.education-permanente.fr/public. Accessed 5122020.
[12] Narcy-combe, Jean. Pierre, 2005: Language teaching and ICT: towards responsible action research, Ophrys, Paris, P. 172.

[13] Pothier, Michel 2003: Multimedia, language learning and acquisition devices, Ophrys, Paris, P. 121.

[14] Porcher Louis and Abdallah-pretceille, Martine, 1998: Ethic of diversity and education, PUF, Pris, p 128.

[15] Seif, Ahmed, 2011: ICTs in the Yemeni education system: from the technical culture of Yemeni society to uses by education professionals, doctoral thesis in language sciences, defended on March 8, 2011, Strasbourg, University of Strasbourg, P. 52. 